\title{
A Relevância da Transmissão da Pesquisa Científica em Psicanálise para a Graduação
}

\author{
Isis Graziele da Silva ${ }^{1}$ \\ ${ }^{1}$ Universidade de São Paulo, SP, Brasil. \\ Laura Carrasqueira Bechara ${ }^{1}$ \\ ${ }^{1}$ Universidade de São Paulo, SP, Brasil.
}

\author{
Rita Dambros Hentz ${ }^{1}$ \\ ${ }^{1}$ Universidade de São Paulo, SP, Brasil. \\ Enzo Cléto Pizzimenti ${ }^{1}$ \\ ${ }^{1}$ Universidade de São Paulo, SP, Brasil.
}

Gabriela Medeiros Rodrigues Aguiar ${ }^{1}$

${ }^{1}$ Universidade de São Paulo, SP, Brasil.

\begin{abstract}
Resumo: Constata-se, a partir da experiência dos autores enquanto psicólogos recém-graduados por diferentes universidades brasileiras, uma desproporção tanto nas oportunidades oferecidas aos graduandos para que se envolvam com pesquisas quanto no que diz respeito à comunicação daquilo que se produz na pós-graduação. Fazendo uso da metodologia de relato de experiência, objetiva-se refletir de que maneira a interlocução entre ensino e pesquisa contribui para a integração entre a graduação e a pós-graduação. Com isso, pretende-se discutir a inserção da psicanálise enquanto método de pesquisa e de produção de saber na universidade, problematizando a relação entre o campo científico e os psicanalistas que se dedicam à atividade de pesquisa. Uma vez que os programas de pós-graduação e os órgãos de fomento de pesquisa priorizam candidatos que tenham experiência em pesquisa científica a fim de selecionar pesquisadores melhor preparados, é fundamental entender como se dá a transmissão da pesquisa em psicanálise para alunos da graduação. A aposta deste trabalho é que a transmissão da pesquisa acadêmica pode suscitar o interesse e a qualificação necessária nos graduandos para o ingresso na pós-graduação, bem como o desenvolvimento da psicanálise enquanto método de pesquisa acadêmica.
\end{abstract}

Palavras-chave: Psicologia, Pesquisa Científica, Pesquisa em Psicanálise, Graduação, Pós-Graduação.

\section{The Relevance of the Transmission of Scientific \\ Research in Psychoanalysis to Undergraduate}

\begin{abstract}
Based on the experience of the authors as psychologists recently graduated from different Brazilian universities, there is a disproportion in the opportunities offered to undergraduates to engage in research and in relation to the communication of what is produced in the graduate courses. Therefore, using the experience reporting methodology, the objective of this work was to think on how the interlocution between teaching and research contributes to the integration between undergraduate and graduate studies. With that, the purpose is to discuss the insertion of psychoanalysis as a method of research and production of knowledge in the university, problematizing the relationship between the scientific field and the psychoanalysts who are engaged in research activity. Since graduate programs and research funding agencies prioritize candidates who have experience in scientific research in order to select better-prepared researchers, it is critical to understand how the transmission of research in psychoanalysis to undergraduates occurs. This work defends that the transmission of academic research can raise the interest and qualification necessary for undergraduate students to join the graduate courses, as well as the development of psychoanalysis as a method of academic research.
\end{abstract}

Keywords: Psychology, Scientific Research, Research in Psychoanalysis, Graduation, Postgraduation. 


\title{
La Relevancia de la Transmisión de la Investigación Científica en el Psicoanálisis para la Graduación
}

\begin{abstract}
Resumen: Según la experiencia de los autores como psicólogos recién graduados de diferentes universidades brasileñas, existe una desproporción tanto en las oportunidades que se ofrecen a los estudiantes de pregrado para involucrarse en la investigación como en la comunicación de lo que se produce en la escuela de posgrado. Utilizando la metodología de informes de experiencia, el objetivo es reflexionar sobre cómo el diálogo entre la enseñanza y la investigación contribuye a la integración entre los cursos de pregrado y posgrado. Con esto, se pretende discutir la inserción del psicoanálisis como método de investigación y producción de conocimiento en la universidad, cuestionando la relación entre el campo científico y los psicoanalistas que se dedican a la actividad de investigación. Dado que los programas de posgrado y las agencias de promoción de la investigación priorizan a los candidatos que tienen experiencia en investigación científica para seleccionar investigadores mejor preparados, es esencial comprender cómo se transmite la investigación del psicoanálisis a los estudiantes universitarios. La apuesta de este trabajo es que la transmisión de la investigación académica puede aumentar el interés y la calificación necesaria en los estudiantes de pregrado para ingresar al postgrado, así como el desarrollo del psicoanálisis como método de investigación académica.
\end{abstract}

Palabras clave: Psicología, Investigación Científica, Investigación en Psicoanálisis, Pregrado, Posgrado.

\section{Introdução}

Desejamos que o emprego da psicanálise na educação cumpra as esperanças que educadores e médicos nela colocam justificadamente (Freud, 1913/2010, p. 343).

Coutinho, Mattos, Monteiro, Virgens e Almeida Filho (2013) assinalam que Freud defendeu a introdução da psicanálise na formação universitária, "levando em consideração sua crença na ciência, na psicanálise como ciência e no papel potencialmente transformador da transmissão e do ensino" (p. 106). Contudo, a entrada da psicanálise nas universidades brasileiras, enquanto referencial teórico e método científico de pesquisa, pode ser considerada um fenômeno recente.

Do ponto de vista formal curricular, essa entrada acontece a partir da década de 1950, e é nos anos 2000, quando acontece o grande impulso da pós-graduação nas universidades brasileiras, que "a presença de psicanalistas nas universidades em cursos de graduação e pós-graduação tornou-se uma realidade" (Coutinho et al., 2013, p. 111). É nesse momento que se tem "um expressivo incremento da produção acadêmica em psicanálise, proveniente da qualificação de psicanalistas no nível de doutorado, tanto em universidades brasileiras quanto estrangeiras" (Coutinho et al., 2013, p. 111).

Safra (2001) faz referência a um processo histórico em que forças antagônicas, advindas tanto do interior como do exterior das universidades, dificultaram o processo de inserção da psicanálise na universidade. De acordo com o autor, os primeiros psicanalistas a adentrarem no contexto universitário no Brasil viam-se impelidos a utilizar metodologias com maior reconhecimento científico a fim de legitimar suas pesquisas, guardando a psicanálise para a interpretação dos dados. Ao mesmo tempo, a Sociedade de Psicanálise também se manifestou contra a inserção dos analistas como professores nas universidades, sob o argumento de que a psicanálise não deveria ser ensinada em outros espaços que não aqueles dedicados exclusivamente à formação de analistas. Ela ainda ameaçou expulsá-los, caso o fizessem (Safra, 2001).

Contudo, graças à persistência desses professores-pesquisadores, o saber psicanalítico ganhou espaço nas instituições de Ensino Superior do país, com o desenvolvimento de trabalhos que se valiam desse saber enquanto teoria e método de investiga- 
ção. Deste modo, logo a universidade também passou a constituir um campo para a expansão dos saberes e de pesquisas psicanalíticas, o que favoreceu o exercício da liberdade associativa (Kupermann, 2009).

Cabe ressaltar que não se pretende propor nesse trabalho que a universidade possa dar conta da formação de um analista, uma vez que esta é atravessada por um desejo específico, o qual não corresponde necessariamente ao desejo do pesquisador que leciona e conduz investigações na universidade. Entretanto, entende-se que o espaço universitário pode ser profícuo para a pesquisa em, de e sobre psicanálise, além de permitir que psicanalistas em formação integrem outros territórios para além de consultórios particulares e associações psicanalíticas.

Não obstante, cabe refletir sobre como tem ocorrido essa integração, entendendo que não é sem tensões que ela acontece, visto que existem demandas institucionais em jogo (tais como a organização da universidade em grades curriculares, os índices de produtividade, as etapas dos processos de seleção, entre outros). No presente trabalho, a atividade de pesquisa em diferentes níveis de formação, a saber, na graduação e na pós-graduação, é tomada como um ponto nodal de discussão.

Objetiva-se, por isso, refletir de que maneira a interlocução entre ensino e pesquisa contribui para a integração entre a graduação e a pós-graduação. Pretende-se discutir a inserção da psicanálise enquanto método de pesquisa e de produção de saber na universidade, problematizando a relação entre o campo científico e os psicanalistas que se dedicam à atividade de pesquisa.

Partindo para uma apreciação das demandas institucionais, uma das formas de se apresentar a universidade enquanto instituição de Ensino Superior é através do seu princípio pautado na tríade ensino-pesquisa-extensão. Além disso, sabe-se que o professor universitário tem como função primordial garantir a propagação do conhecimento e sustentar a produção de pesquisas científicas implicadas com as questões da comunidade à qual pertence. No entanto, percebe-se que não existe consenso sobre como esses eixos e essa tarefa deverão ser realizados nos diferentes projetos político-pedagógicos das universidades.

No Brasil, tem-se um cenário no qual a educação superior encontra-se bipartida entre cultura acadêmica e cultura profissional, o que resulta em dois tipos de formação distintos. Para Breglia (2013), um dos desafios enfrentados pela universidade nos dias de hoje é articular a tradição de pensamento crítico e reflexivo - que segue seu próprio ritmo -, com as demandas de nosso tempo. A autora aponta que a capacidade de responder a mudanças deve ser prioridade na formação universitária, e acreditamos que esta maleabilidade deve ser encontrada no processo de pesquisa, que tem como intenção produzir respostas, bem como propor novas questões em um campo. Desse modo, a pesquisa é condição para a capacidade de dar respostas às questões da atualidade.

Uma das consequências da referida bipartição no Ensino Superior, entretanto, é que a atividade de pesquisa mais ligada à cultura acadêmica é frequentemente privilegiada no nível da pós-graduação, em detrimento da graduação. A esta última fica reservada a formação profissional, o que muitas vezes implica em sua desvalorização enquanto espaço potencial de produção de conhecimento, para além da simples apreensão e reprodução de saberes.

Cabe lembrar que essa conjuntura remete ao próprio estabelecimento das universidades no país. Como Sampaio (1991) aponta, a compreensão da relevância da pesquisa é um dos elementos que fez renascer o debate sobre a função da universidade, nas primeiras décadas do século XX. A universidade, como lembra a autora,

Havia que abrigar a pesquisa de modo estável, e promover a formação do pesquisador, que estava presa, até então, às escolas profissionais inadequadas para esse fim. A pesquisa precisava de um espaço mais distanciado de resultados práticos, e com mais liberdade de experimentação e de pensamento. O debate sobre a criação de uma universidade no Brasil ressurge em uma nova perspectiva. Ele rompia com a argumentação quase estritamente política que havia vigorado ao longo de todo o século XIX e agora atribuía à instituição universitária uma nova função: abrigar a ciência, os cientistas e as humanidades em geral e promover a pesquisa (Sampaio, 1991, p. 8).

Pressupõe-se que a postura investigativa deve perpassar não apenas os espaços em que a pesquisa é privilegiada, como a pós-graduação, mas todo o trajeto de formação universitária. Isto porque, além da transmissão teórica ensejada para a graduação, o contato com as pesquisas desenvolvidas ou em desen- 
volvimento pode suscitar no graduando a desejada posição de curiosidade frente ao saber. Posição esta fundamental para a produção de ciência nas universidades, embora seja postergada e objetivada apenas no contexto da pós-graduação.

Primordialmente, para pensar na transmissão em questão (da pós-graduação para a graduação), faz-se importante definir pesquisa em psicanálise. Freud (1923/2011), em "Dois verbetes de enciclopédia", caracterizou a psicanálise a partir de três eixos fundamentais: como uma forma de tratamento, como uma teoria metapsicológica e como um método de investigação, isto é, de pesquisa. No entanto, diferentemente de outros campos teóricos, na psicanálise esses três aspectos estão sempre relacionados e são interdependentes, o que ainda suscita certos preconceitos em relação à aplicação dessa teoria na pesquisa científica.

No legado freudiano, é possível perceber uma importante preocupação em tornar a psicanálise uma ciência legítima e reconhecida. Todavia, apesar do espaço que ganhou nas universidades, a busca pelo reconhecimento científico da psicanálise ainda é atual nos cenários acadêmicos brasileiros. Nesse sentido, é possível observar que as dificuldades encontradas para essa legitimação produzem prejuízos, como a escassa transmissão da pesquisa em psicanálise para alunos da graduação.

Essa "pesquisa em psicanálise" que pode (e deve) ser transmitida nos remete à ênfase dada por Mezan (2006, p. 232) de que

na universidade - em particular na pós-graduação - vêm sendo realizados trabalhos a que se pode chamar sem medo "pesquisa psicanalítica”. Eles poderiam perfeitamente ser apresentados nas Sociedades, Círculos e associações semelhantes para conferir a seus autores este ou aquele grau: em nada diferem dos que costumam servir a este propósito, exceto talvez por um rigor maior. A universidade interessou-se pela questão por uma razão muito simples: para escrever dissertações e teses em psicanálise e de psicanálise, é necessário pesquisar no sentido forte deste termo. E a prova de que tais trabalhos são úteis para o psicanalista não-acadêmico está no fato de que hoje se tornou comum estudar em livros gestados nas incubadoras da pós-graduação.
Entretanto, constata-se, especialmente a partir da experiência dos autores enquanto psicólogos graduados entre 2015 e 2016 por diferentes universidades brasileiras (Universidade Federal de Uberlândia, Pontifícia Universidade Católica do Rio Grande do Sul, Universidade de São Paulo, Universidade Presbiteriana Mackenzie e Universidade Federal do Ceará), uma significativa desproporção tanto nas oportunidades oferecidas aos graduandos de envolvimento com pesquisas quanto na comunicação daquilo que se produz na pós-graduação.

Este dado chama a atenção, especialmente ao compreendermos que indica cenários da graduação em Psicologia de pelo menos quatro estados brasileiros. E é com base nesta observação que se chama atenção para a importância de que os psicanalistas inseridos na universidade situem de maneira mais veemente a interlocução entre pesquisa e ensino para os graduandos, apresentando-lhes a pesquisa em psicanálise como produtora de conhecimento de relevância científica. Nessa esteira, Elia (2009) os convoca a se posicionarem "de modo menos tímido, envergonhado, ou orgulhosamente ludibriado pela ostentação de um lugar pretensamente independente da ciência" (p. 36-37).

\section{Método}

Tendo em vista a origem dos questionamentos e discussões que culminaram na produção do presente trabalho - a saber, as reverberações de intensos debates ocorridos no decorrer do mestrado no Programa de Pós-Graduação em Psicologia Clínica do Instituto de Psicologia da Universidade de São Paulo - optou-se pelo relato de experiência enquanto método de produção de conhecimento científico, atrelado à construção feita a posteriori com o levantamento bibliográfico realizado pelos autores.

Aqui surge um elemento essencial que merece ser destacado. Ao apostar no relato de experiência, busca-se produzir uma pesquisa que se sustente a partir do contexto institucional e espaço-temporal em que os questionamentos foram suscitados. Desta maneira, trata-se de uma escrita e de uma produção implicadas e articuladas com a tensão oriunda do ponto de partida da pesquisa, qual seja: a percepção da escassa transmissão de pesquisas em psicanálise na graduação em Psicologia dos autores deste trabalho. Em conformidade com as proposições de Amorim (2002), ao utilizar da experiência dos autores, objetiva-se um reencontro 
com a dimensão do acontecimento que produziu a pesquisa, sustentando e apostando na potência polifônica, aliada ao encontro entre forma e conteúdo, donde se faz possível ouvir a voz dos autores.

Desta feita, partir-se-á para uma apreciação das exigências do processo seletivo para ingresso no mestrado do Programa supracitado, seleção à qual todos os autores do presente trabalho foram submetidos. Tais aspectos serão contrastados com a presença ou ausência de modalidades de incentivo à atividade de pesquisa no momento anterior de suas formações, como já referido, na graduação em Psicologia em suas respectivas universidades de origem, de modo a apresentar elementos suficientes para construir o recorte de uma discussão em torno do assunto.

\section{Resultados}

Como requisitos para o processo seletivo de mestrado em Psicologia Clínica no Instituto de Psicologia da Universidade de São Paulo no final do ano de 2016, os candidatos deveriam apresentar, junto com seus currículos Lattes, uma proposta de projeto de pesquisa que segue uma estrutura pré-estabelecida pelo Programa. As etapas do processo consistiram em duas provas eliminatórias (uma de proficiência em inglês e a outra de conhecimentos básicos em Psicologia Clínica), e em uma prova classificatória (de análise do projeto e do currículo do candidato). A etapa classificatória aconteceu no formato de entrevista, na qual os candidatos foram questionados acerca de seu percurso profissional e de sua experiência em pesquisa.

Uma vez aprovados no mestrado, os alunos que desejam pleitear uma das bolsas de fomento à pesquisa devem passar por um segundo processo de seleção, no qual seus respectivos currículos Lattes e projetos de pesquisa são avaliados de acordo com determinados critérios de pontuação, gerando, ao final, uma lista de classificação. No ano de 2017, o Programa de Pós-graduação em Psicologia Clínica teve em torno de quarenta candidatos aprovados no processo seletivo para as vagas de mestrado, entretanto, foi contemplado com apenas dez bolsas Coordenação de Aperfeiçoamento de Pessoal de Nível Superior (Capes) ou Conselho Nacional de Desenvolvimento Científico e Tecnológico (CNPq) para essa modalidade.

Foram divulgados pelo Programa os seguintes critérios de pontuação, definidos para a classificação de candidatos à bolsa:
- projeto de pesquisa avaliado por seus objetivos, fundamentação, metodologia, viabilidade e relevância do tema para a área (5 pontos);

- qualidade na escrita, clareza na redação, com argumentação pertinente ao tema, linguagem adequada, estrutura ordenada, coesão e coerência (5 pontos);

- potencial do candidato como pesquisador, avaliado pelo histórico escolar e pelo currículo - quantos artigos, quantos trabalhos completos em anais, quantas participações em congressos etc. (10 pontos).

A partir deste panorama, cabe fazer dois apontamentos. Percebe-se que a produção acadêmica e a dedicação à pesquisa são consideradas pré-requisitos importantes no perfil do candidato ensejado. Entretanto, é sabido que, no Brasil, as pesquisas em Psicologia têm lugar quase exclusivamente dentro de instituições de Ensino Superior, a despeito de outras áreas do conhecimento que podem, por exemplo, contar com maior incentivo da iniciativa privada e ter lugar em outros espaços que não o acadêmico. Seguindo esse raciocínio, é possível inferir que a oportunidade de dedicação à pesquisa e produção acadêmica anterior ao mestrado, no caso de psicólogos, se dê na graduação.

O segundo apontamento remete à experiência profissional desejável por parte dos candidatos, a qual lhes garantiria uma maior vivência dos desafios e problemáticas pertinentes à profissão ou à inserção da sua área de conhecimento na sociedade. Em um cenário ideal, seria o encontro com essas questões que movimentaria a atividade de pesquisa, uma vez que suscitaria questionamentos importantes a serem estudados no contexto acadêmico. Como já discutido, é corrente o entendimento de que a graduação tenha o papel de formação do profissional, possibilitando essa inserção no mercado de trabalho; todavia, tem-se aqui a percepção de que essa prática poderia estar atrelada a uma postura de pesquisa, que nem sempre é privilegiada na formação profissionalizante.

$\mathrm{Na}$ experiência dos autores em seus respectivos cursos de graduação, aconteceram apresentações da psicanálise e da pesquisa psicanalítica, algumas das quais serão agora relembradas para fomentar uma reflexão mais aprofundada sobre os dois apontamentos feitos. As experiências serão relatadas de forma a não identificar a universidade específica em que se 
deram, pois considera-se que esta identificação não é necessária para os objetivos deste trabalho.

Uma das autoras, em sua graduação em Psicologia, passou por duas disciplinas obrigatórias de psicanálise no primeiro ano do curso, as quais não se constituíram em uma aproximação didática da graduanda com tal conteúdo, até então desconhecido. Somente no quarto ano de curso uma disciplina optativa, curiosamente chamada de "Psicanálise II", foi oferecida, com o intuito de servir como uma introdução à teoria psicanalítica. Foi esta disciplina que esclareceu, finalmente, algumas das lacunas deixadas pelas disciplinas obrigatórias anteriores. De uma forma geral, as três abordaram apenas o corpo teórico freudiano, e só houve contato com autores pós-freudianos em cursos e eventos dos quais a autora participava fora da universidade.

No curso da disciplina do quarto ano, a professora propôs que os alunos utilizassem os conceitos trabalhados em aula para a reflexão acerca de temas do interesse e do cotidiano deles, e foi esta interessante experiência de pesquisa que motivou a autora a se propor a fazer o seu trabalho de conclusão de curso utilizando a abordagem psicanalítica, sob a orientação da referida professora. O sucesso da disciplina foi tamanho que vários alunos desejaram se inscrever nos semestres subsequentes, mas ela não foi oferecida novamente.

Nessa universidade, os graduandos não eram advertidos sobre a importância da produção de artigos científicos, mas somente aconselhados a pensarem sobre isso, depois de finalizarem o trabalho de conclusão de curso, isto é, justamente ao finalizarem a graduação. E se a elaboração era levada a cabo, em geral acontecia sem qualquer supervisão de professores. Cabe ressaltar que até o momento da graduação dessa autora, este Instituto de Psicologia contava apenas com mestrado como modalidade de pós-graduação.

Em outra das universidades, a grade curricular comportava duas disciplinas obrigatórias que tinham como foco a psicanálise, sendo uma de princípios básicos e outra de epistemologia. Além disso, havia uma disciplina de ênfase curricular em clínica que visava oferecer ao graduando um maior escopo técnico e teórico para início dos estágios obrigatórios. Também eram oferecidas as disciplinas de pesquisa e de monografia em Psicologia, das quais apenas a primeira era obrigatória. Para cada uma delas, o aluno poderia eleger um professor como orientador; entretanto, havia pouca disponibilidade de professores para essa atividade, o que correntemente levava os alunos a tomarem parte em pesquisas muito destoantes de suas temáticas de interesse.

O principal espaço de transmissão do saber psicanalítico, para a autora ali graduada, foi um núcleo de pesquisa e extensão que reunia os professores de abordagem psicanalítica daquele departamento e seus respectivos orientandos, o qual oferecia aos graduandos um grupo de estudos de introdução à psicanálise. Além disso, cada pós-graduando deveria oferecer um grupo de estudos aberto ao público de um tema adjacente à sua pesquisa como prática de estágio em docência. O núcleo dispunha, ainda, de atividades regulares mais ligadas ao eixo da extensão, das quais se encarregavam, principalmente, bolsistas advindos dos primeiros anos da graduação, a fim de lhes proporcionar bases para inserção no campo da pesquisa.

Pode-se dizer que o incentivo à produção acadêmica dependia do perfil do núcleo em que o aluno de graduação se inseria. As produções científicas eram resultado de longos trabalhos de pesquisa (de iniciação científica e/ou de monografia) e, quase sempre, restritas a poucas publicações, para garantir o rigor teórico-metodológico de cada uma delas. A participação em eventos, em contrapartida, era fortemente incentivada a todos os membros, sem distinção quanto ao nível de formação.

Na terceira experiência de graduação a ser apresentada, a introdução à psicanálise consistiu em uma primeira disciplina obrigatória de introdução à Psicologia Clínica: história e fundamentos, no primeiro ano. A partir de uma aproximação inicial com a metapsicologia freudiana, outras disciplinas obrigatórias deram seguimento ao ensino do corpo teórico psicanalítico. Uma das críticas feitas por graduandos era a repetição dos textos fundamentais em todas as disciplinas, atribuída ao pouco diálogo entre os docentes a respeito de suas aulas.

Nessa terceira universidade, as disciplinas que apresentam as noções para a condução de tratamento, construção de hipóteses diagnósticas e de projetos terapêuticos são optativas. Aquela que é considerada como a principal disciplina, no que tange à transmissão da psicanálise enquanto método de tratamento, é a de atendimento clínico, na qual as funções de supervisor e docente se entrelaçam. Além da experiência de 
atendimento clínico, essa autora pôde participar de uma disciplina optativa intitulada "Pesquisa em Psicologia Clínica e Psicanálise”, a partir da qual floresceu o desejo de continuar o percurso de pesquisa em psicanálise na pós-graduação.

Já em outra experiência de graduação, apesar de a psicanálise estar presente no currículo desde o segundo semestre e ter forte influência na formação dos estudantes, havia pouco espaço para essa linha teórica na pós-graduação. O programa contava com mais de vinte grupos de pesquisas, sendo apenas um de psicanálise. Em decorrência disso, poucos alunos de graduação desfrutavam da oportunidade de aproximar-se da pesquisa em psicanálise, uma vez que as vagas não correspondiam à grande demanda.

Além disso, muitos alunos passaram anos sem conhecer ou participar das atividades de pós-graduação, como as defesas de mestrado e de doutorado, uma vez que a transmissão de informações para os graduandos falhava ou deixava de acontecer. Dessa forma, muitos estudantes desconheciam também a importância de construir um bom currículo durante a graduação, e acabaram sentindo as consequências disso nas seleções de estágio. Contudo, anualmente acontecia um evento com o objetivo de aproximar a graduação da pós-graduação, mediante a apresentação de trabalhos feitos pelos graduandos ao longo do curso, os quais eram avaliados pelos pós-graduandos e posteriormente publicados nos anais do evento.

Na última experiência a ser relatada, a psicanálise foi apresentada no segundo semestre de graduação, no qual foram apresentados os conceitos freudianos fundamentais, e o semestre seguinte contemplou o desenvolvimento teórico de autores pós-freudianos. Embora as disciplinas sobre pesquisa tenham iniciado desde o primeiro semestre, não houve nenhuma que articulasse pesquisa e psicanálise.

Uma experiência que indicou a resistência de outras abordagens em relação à psicanálise se deu no terceiro ano, em uma disciplina de pesquisa na qual o autor se propôs a utilizar conceitos psicanalíticos, mas teve a sua iniciativa rechaçada, sob o argumento de que tais conceitos eram muito avançados para a graduação. Além disso, disciplinas optativas ou a possibilidade de monitoria em pesquisas articuladas à psicanálise não foram oferecidas para os graduandos. Vale ressaltar que até o ano de 2017 não havia programa de mestrado e/ou doutorado nesta universidade.

\section{Discussão}

Partindo dos relatos apresentados, são oportunas algumas considerações que busquem vislumbrar caminhos para se sobrepujar os impasses já apresentados.

Lo Bianco (1996), ao elencar possibilidades de contribuição da pós-graduação frente aos entraves encontrados pela graduação em Psicologia, refere-se à ênfase da primeira ao conhecimento produtivo, em detrimento daquele meramente reprodutivo. Para a autora, "[...] o envolvimento de um pesquisador com os procedimentos [de pesquisa] o levam a questionar o estatuto do conhecimento, que se apresenta, assim, como um conhecimento em permanente processo de construção/desconstrução" (Lo Bianco, 1996, p. 27).

Para Severino (2009), tal processo de construção e desconstrução do conhecimento tem caráter formativo e pedagógico e depende dos alunos da graduação e pós-graduação. Nesse sentido, reitera a importância da pesquisa enquanto espaço de trabalho coletivo, em constante manutenção com a entrada e saída de pesquisadores de um grupo. Seria relevante, portanto, que a composição de um grupo de pesquisa pudesse contemplar de forma efetiva, além dos pós-graduandos (que já estão mais familiarizados com a prática sistemática de investigação científica), os alunos de graduação.

Os programas institucionais de iniciação científica desempenham um papel importante nessa integração, na medida em que se propõem a incentivar a formação de pesquisadores desde a graduação e a preparar profissionais mais críticos (Breglia, 2013). Entretanto, percebe-se que essa realidade ainda não é muito incentivada em nosso país e que a quantidade de projetos de iniciação científica em vigor é muito menor do que a quantidade de alunos que gostariam de tomar parte neles. Como resultado, muitas vezes os estudantes se veem obrigados a aceitar qualquer oportunidade, mesmo que o projeto não se refira ao tema de seu maior interesse.

Na experiência dos autores desse texto, a possibilidade de participação, ou mesmo o conhecimento sobre os grupos de pesquisa existentes, surgiu apenas na segunda metade da graduação. Tem-se como exemplo que uma das autoras foi convidada por um professor para iniciar as atividades práticas de um determinado projeto, sem nenhuma instrução quanto ao fato de se tratar de uma iniciação científica, nem quanto ao fato de este ser um apêndice de uma pes- 
quisa muito maior, já há algum tempo em andamento com vários outros pesquisadores.

Severino (2009) adverte que a introdução na atividade científica realizada durante a graduação coloca o aluno em contato com práticas marcadas pelo rigor, seriedade, metodicidade e sistematicidade que contribuem para seu desenvolvimento profissional e acadêmico. Para que esta inserção se faça de maneira potente é essencial que haja, em primeiro lugar, uma apresentação das referências epistemológicas para que, posteriormente, seja viabilizada uma entrada menos desavisada nos debates atuais acerca das questões inerentes à produção científica.

Compreende-se que, a par da teoria e em contato com as premissas científicas, o aluno pode traçar um caminho mais crítico e reflexivo em relação ao que já é conhecido e produzido em sua área de investigação. Contudo, observa-se que, pelo desconhecimento sobre as pesquisas em curso na pós-graduação e pela superficialidade do aprendizado sobre as questões epistemológicas, os autores não tiveram orientação no processo de elaboração do projeto de pesquisa de mestrado.

Outro elemento a ser destacado consiste na importância de a pós-graduação estar comprometida com a formação do professor-pesquisador, para que o saber construído em pesquisa se torne passível de transmissão a partir de métodos menos verticais e mais inventivos. Por isso, a proximidade da graduação com a pós-graduação é uma vantagem dupla: além de facilitar o percurso de futuros pesquisadores, é também um exercício significativo de docência para os pós-graduandos e um meio de comunicação democrático da sua produção. Isto porque é preparando o bom pesquisador que se prepara o bom professor universitário ou qualquer outro profissional (Severino, 2009).

Mas outra questão também exorta reflexões: se a interlocução entre graduação e pós-graduação é tão profícua, e se a transmissão teórica é insuficiente para uma formação completa na graduação, o que dizer então do ensino da psicanálise, que em si mesma é um método investigativo?

Nogueira (2004) enfatiza que a psicanálise é, por si só, pesquisa, retomando o que Freud (1912/1969, p. 152) afirmara: "a psicanálise faz em seu favor a reivindicação de que, em sua execução, tratamento e investigação coincidem". Desta forma, seu ensino e transmissão poderão levar o aluno, posteriormente, a práticas embasadas no método de investigação psicanalítico. Quando Freud definiu a psicanálise em 1923, já indicava que seu exercício é o de construir conceitos sobre a experiência, pois, se isso não for feito, ela não cresce em termos de conhecimento. Como ensina Rosa (2001), não basta levar o sujeito à descoberta da psicanálise por meio de seus conceitos, é preciso engendrar o modo específico da psicanálise de produzir conhecimento.

Sendo assim, seria suficiente, na graduação, a presença exclusiva de disciplinas teóricas e expositivas acerca da psicanálise, sem que haja o contato com pesquisas de metodologia psicanalítica?

A pesquisa, atrelada ao rigor acadêmico, permite que a psicanálise se repense em outros contextos, $o$ que é importante para que as suas contribuições (de leitura do mal-estar, dos sofrimentos e sintomas do sujeito e dos grupos) possam se articular por meio de suas diferenças com outros campos do saber. Além disso, conforme aponta Loureiro (2002 citado por Kupermann, 2009), a pesquisa psicanalítica pode aliar as exigências do rigor acadêmico com as especificidades da "disposição metodológica" característica do pensamento freudiano, acarretando, aqui também, em contribuições de mão-dupla, a partir do estreitamento das relações entre a psicanálise e a universidade. Tais indicações remetem à questão colocada por Elia (2009, p. 37) sobre o posicionamento do psicanalista:

Quando seremos capazes de assumir nossa posição em face da ciência, que é de intimidade discursiva, origem comum, filiação, derivação, ou como melhor denominemos esse importante vínculo que, [...] envolve antes dependência discursiva do que uma arrogante independência que só reforça a servidão imaginária e obscurantista a troncos não científicos do pensamento [...]?

\section{Considerações finais}

A proposta de refletir sobre a integração no curso de Psicologia da graduação com a pós-graduação, interessada especialmente no que tange a transmissão da psicanálise, surgiu do espanto dos autores ao se depararem com questões problemáticas vividas e observadas em diferentes universidades do país e do reconhecimento que isso provocou entre eles. 
Ao se encontrarem no mestrado do Instituto de Psicologia da Universidade de São Paulo, experimentaram debates que apontaram para uma desproporção tanto nas oportunidades oferecidas aos graduandos para que se envolvam com pesquisas quanto no que diz respeito à comunicação daquilo que se produz na pós-graduação.

Por isso, fazendo-se uso da metodologia de relato de experiência, este trabalho buscou compartilhar e levar adiante a reflexão sobre a forma com que a interlocução entre ensino e pesquisa pode contribuir para a integração entre a graduação e a pós-graduação. Nesse sentido, refletiu-se também sobre a inserção da psicanálise enquanto método de pesquisa e de produção de saber na universidade, problematizando a relação entre o campo científico e os psicanalistas que se dedicam à pesquisa.

Uma vez que os programas de pós-graduação e os órgãos de fomento de pesquisa priorizam candidatos que tenham experiência em pesquisa científica a fim de selecionar pesquisadores melhor preparados, é fundamental entender como se dá a transmissão da pesquisa em psicanálise para alunos da graduação. Por isso, a aposta deste trabalho é que a transmissão da pesquisa acadêmica possa suscitar o interesse e a qualificação necessária nos graduandos para o ingresso na pós-graduação, bem como o desenvolvimento da psicanálise.

A partir dos apontamentos apresentados no texto, percebe-se que a atividade de pesquisa revela-se como um articulador importante entre a graduação e a pós-graduação em Psicologia, o que ganha ainda maior relevo no âmbito das investigações em psicanálise, dado seu caráter singular de ser, ao mesmo tempo, uma teoria, um método clínico e um método de pesquisa, conforme definido por Freud (1923/2011).

A polarização sobre a qual se edifica o Ensino Superior brasileiro, que força a separação entre a formação acadêmica e a formação profissional, dificulta que a produção de conhecimento nesses espaços esteja implicada com as demandas sociais de nosso tempo, de modo a frustrar um dos princípios fundamentais a que se destina o trabalho universitário. Nessa conjectura, é possível observar implícita a ideia da graduação como um espaço de mera reprodução de conhecimento, e não como potência de construção de saber. Esse processo Breglia (2013) denominou de "escolarização da graduação" (p. 11), que ao ser enquadrada como um "ensino de segunda classe" (p. 11) justificaria muitas vezes o afastamento de professores e pesquisadores importantes desse contexto, de modo a aprofundar a distância existente entre aquela e a pós-graduação.

A atividade de pesquisa, por sua vez, ganha destaque justamente como possibilidade de superação dessa problemática, já que não se restringe ao trabalho acadêmico, mas permeia todo e qualquer espaço que busque dar respostas às questões atuais. Para isso, faz-se necessário incentivar o aluno, em qualquer nível de formação, à adoção de uma postura investigativa em quaisquer de suas práticas. No que tange à psicanálise, é esse posicionamento que propicia o seu desenvolvimento, pois, como defendia Freud (1923/2011, p. 301):

[A psicanálise] está sempre incompleta, sempre disposta a ajustar ou modificar suas teorias. Tal como a física e a química, ela tolera muito bem que seus principais conceitos sejam vagos e seus pressupostos sejam provisórios, e espera uma maior precisão deles como resultado de trabalho futuro.

Como experiências positivas com a pesquisa em psicanálise durante a graduação dos autores deste trabalho, pode-se elencar: o convite a refletir sobre um tema de interesse utilizando conceitos psicanalíticos aprendidos até então; a possibilidade de dialogar e trabalhar juntamente com pós-graduandos dentro de um grupo de pesquisa e extensão; a oportunidade de cursar uma disciplina optativa com temática voltada para pesquisa em Psicologia Clínica e psicanálise; e a participação em eventos de produção científica com o objetivo de aproximar os graduandos da pós-graduação.

Em consequência das experiências relatadas e da problematização construída a partir delas, temos que a pesquisa em psicanálise pode ser colocada de forma mais presente e aprofundada no percurso dos graduandos, de tal feita que ela se mantenha como uma ciência viva, isto é, que se desenvolve enquanto método de pesquisa acadêmica. Compreende-se, assim, que a graduação e a pós-graduação, de um modo geral, deveriam ser menos apartadas uma da outra, pensadas com uma interlocução, um funcionamento e um cotidiano mais integrados, no qual as trocas sejam intrínsecas ao seu modus operandi. 
A partir das reflexões propostas, é possível depreender ainda que a pós-graduação não deveria ter seu foco voltado tão exclusivamente à atividade de pesquisa, mas deveria responsabilizar-se de maneira mais veemente pela formação de pesquisadores engajados também com a docência voltada à graduação. E isso seria possível se, de fato, os programas de pós-graduação estivessem mais envolvidos com a formação dos graduandos. Para tanto, seria necessário um esforço de ponderação sobre as atividades curriculares básicas propostas por programa e sobre o alcance e objetivos dos eventos científicos promovidos.

Elia (2009) chama atenção para a importância de um posicionamento no qual o psicanalista se esquiva da questão do lugar da psicanálise face à ciência, convocando, para tanto, a ética da psicanálise como justificativa. É justamente por ter em vista a ética da psicanálise que o psicanalista não pode promo- ver essa divisão imaginária, segundo a qual haveria, de um lado, a boa ciência (produzida e debatida por psicanalistas pesquisadores), e de outro, a má ciência (não merecedora da atenção deles). Romper com essa divisão imaginária não significaria, necessariamente, compactuar com os princípios que fundamentam o saber científico hegemônico, que são pautados, muitas vezes, em uma lógica produtiva passível de objetificação dos sujeitos.

Uma das apostas deste trabalho é que, ao sustentar a sua ética frente à lógica da ciência hegemônica, o psicanalista abre espaço para a construção de ferramentas que incluem o lugar do sujeito do desejo e suas manifestações erráticas. Vale lembrar (não só neste trabalho, mas a todo momento) que, desde os primórdios da psicanálise, Freud não recuou ante a escuta e a problematização das questões que sustentam a psicanálise enquanto tratamento e método de pesquisa. Por que, então, recuaríamos hoje?

\section{Referências}

Amorim, M. (2002). Vozes e silêncio no texto de pesquisa em Ciências Humanas. Cadernos de Pesquisa, (116), 7-19. https://doi.org/10.1590/S0100-15742002000200001

Breglia, V. L. A. (2013). Graduação, formação e pesquisa: entre o discurso e as práticas. Trivum - Estudos Interdisciplinares, 5(1), 1-4. Recuperado de http://pepsic.bvsalud.org/scielo.php?script=sci_arttext\&pi$\mathrm{d}=\mathrm{S} 2176-48912013000100002$

Coutinho, D. M. B, Mattos, A. S., Monteiro, C. F. A., Virgens, P. A., \& Almeida Filho, N. M. (2013). Ensino da psicanálise na universidade brasileira: Retorno à proposta freudiana. Arquivos Brasileiros de Psicologia, 65(1), 103-120. Recuperado de http://pepsic.bvsalud.org/scielo.php?script=sci_arttext\&pid=S1809-52672013000100008

Elia, L. (2009). Por uma psicanálise desavergonhada diante da ciência. In H. Caldas, \& S. Altoé (Org.), Psicanálise, universidade e sociedade (pp. 29-37). Rio de Janeiro: Companhia de Freud.

Freud, S. (2011). 'Psicanálise’ e ‘Teoria da Libido’ (dois verbetes para um dicionário de sexologia). In S. Freud, Obras Completas (v. 15, P. C. de Souza, trad.). São Paulo: Companhia das Letras. (Originalmente publicado em 1923).

Freud, S. (2010). Prefácio a 'O método psicanalítico', de Oskar Pfister. In S. Freud, Obras completas (v. 10, P. C. de Souza, trad.). São Paulo: Companhia das Letras. (Originalmente publicado em 1913).

Freud, S. (1969). Recomendações aos médicos que exercem a psicanálise. In J. Salomão (Org.), Edição standard brasileira das obras psicológicas completas de Sigmund Freud (v. 12), Rio de Janeiro: Imago. (Originalmente publicado em 1912).

Kupermann, D. (2009) Sobre a produção psicanalítica e os cenários da universidade. Psico, 40(3), 300-307. Recuperado de http://revistaseletronicas.pucrs.br/ojs/index.php/revistapsico/article/view/6597

Lo Bianco, A. C (1996). O ponto de articulação entre graduação e pós-graduação. In E. M. Bonfim. Formaçães em psicologia: Pós-graduação e graduação. (pp. 19-30, Coletâneas da ANPEPP, n. 8). Rio de Janeiro: Associação Nacional de Peesquisa e Pós-graduação em Psicologia.

Mezan, R. (2006). Pesquisa em psicanálise: algumas reflexões. Jornal de Psicanálise, 39(70), 227-241. Recuperado de http://pepsic.bvsalud.org/scielo.php?script=sci_arttext\&pid=S0103-58352006000100015

Nogueira, L. C. (2004). A pesquisa em psicanálise. Psicologia USP, 15(1-2), 83-106. https://doi.org/10.1590/S0103-65642004000100013 
Rosa, M. D. (2001). Psicanálise na universidade: Considerações sobre o ensino de psicanálise nos cursos de Psicologia. Psicologia USP, 12(2), 189-199. https:// doi.org/10.1590/S0103-65642001000200016

Safra, G. (2001). Investigação em Psicanálise na Universidade. Psicologia USP, 12(2), 171-175. https:// doi.org/10.1590/S0103-65642001000200014

Sampaio, H. (1991). Evolução do ensino superior brasileiro (1808-1990) ( Documento de trabalho 8/91). São Paulo: Núcleo de Pesquisa sobre Ensino Superior da Universidade de São Paulo.

Severino, A. J. (2009). Pós-graduação e pesquisa: O processo de produção e de sistematização do conhecimento. Diálogo Educacional, 9(26), 13-27. https://doi.org/10.7213/rde.v9i26.3640

\section{Isis Graziele da Silva}

Psicóloga, Discente da Universidade de São Paulo, São Paulo - SP. Brasil.

E-mail: isisgraziele@usp.br

(iD https:// orcid.org/0000-0001-5486-6545

\section{Rita Dambros Hentz}

Psicóloga, Discente da Universidade de São Paulo, São Paulo - SP. Brasil.

E-mail: ritahentz@usp.br

(iD) https://orcid.org/0000-0003-1920-6028

\section{Laura Carrasqueira Bechara}

Psicóloga, Discente da Universidade de São Paulo, São Paulo - SP. Brasil.

E-mail: laura.bechara@usp.br

(iD https:// orcid.org/0000-0002-6397-6508

Enzo Cléto Pizzimenti

Psicólogo, Discente da Universidade de São Paulo, São Paulo - SP. Brasil.

E-mail: enzopizzimenti@usp.br

(iD https:// orcid.org/0000-0001-7336-8947

Gabriela Medeiros Rodrigues Aguiar

Psicóloga, Discente da Universidade de São Paulo, São Paulo - SP. Brasil.

E-mail: gabrielamra@usp.br

(iD) https:// orcid.org/0000-0003-0605-6403

Endereço para envio de correspondência:

Rua Vieira Fazenda, n 30 - Cj. 3. CEP: 04117-030. São Paulo - SP. Brasil.

Recebido 07/05/2018

Reformulado 25/04/2019

Aceito 24/07/2019

Received 05/07/2018

Reformulated $04 / 25 / 2019$

Approved 07/24/2019

Recibido 07/05/2018

Reformulado 25/04/2019

Aceptado 24/07/2019 
Como citar: Silva, I. G., Hentz, R. D., Bechara, L. C., Pizzimenti, E. C., \& Aguiar, G. M. R. (2020). A relevância da transmissão da pesquisa científica em psicanálise para a graduação. Psicologia: Ciência e Profissão, 40, 1-12. https://doi.org/10.1590/1982-3703003198099

How to cite: Silva, I. G., Hentz, R. D., Bechara, L. C., Pizzimenti, E. C., \& Aguiar, G. M. R. (2020). The relevance of the transmission of scientific research in psychoanalysis to undergraduate. Psicologia: Ciência e Profissão, 40, 1-12. https://doi.org/10.1590/1982-3703003198099

Cómo citar: Silva, I. G., Hentz, R. D., Bechara, L. C., Pizzimenti, E. C., \& Aguiar, G. M. R. (2020). La relevancia de la transmisión de la investigación científica en el psicoanálisis para la graduación. Psicologia: Ciência e Profissão, 40, 1-12. https://doi.org/10.1590/1982-3703003198099 